\title{
Le Mur
}

Rayonnement lilial dans les limbes des nuits quelle averse s'étend en nos bras malheureux Un poète paraît-il su chanter le chanceux la cambrure des cieux remplis de certitude Mais en cette traversée des veines assiégées ont clos l'univers d'un langage éclairé car le mal a inondé sans pitié les braises d'un jour qui n'a su saisir ni tort ni tristesse La circularité d'un appel rapproché siège dans la contrainte d'une fixité où l'oubli s'impose et l'image se rompt Qu'est-ce qui peut éloigner de ce vain mirage qu'une amitié réelle ne sait apaiser Alors que tout suggère un dessein physique les ramages de la view parcourent l'allée privée du bonheur des rayons jumelés

$$
* * *
$$

\section{Les Ecueils}

La vie est par-delà l'ultime assaut des écueils tremblants

Le coin de seuil laurd est sa falaise

raclée jusqu'à la moelle moissonneuse est sa candeur sous l'arche tortide de la mémoire Le passé se rassemble en moue délicate pour former cet enjeu détalant où les frontières ont su discerner un espace incernable où la lumière sans pesanteur s'insère vaporeuse dans les pores d'un ciel vierge où les archanges de la nuit tissent une toile encore si frêle sous l'ampleur du jour 